\title{
Acute toxicity of methyl isocyanate: a preliminary study of the dose response for eye and other effects
}

\author{
A GSALMON,${ }^{1}$ M KERR MUIR, ${ }^{2}$ AND N ANDERSSON ${ }^{1}$ \\ From the TUC Centenary Institute of Occupational Health, ${ }^{1}$ London School of Hygiene and Tropical Medicine, \\ London WCIE 7HT, and Moorfields Eye Hospital, ${ }^{2}$ London ECIV 2PD, UK
}

ABSTRACT Acute toxic effects of methyl isocyanate in the rat were determined for two hour exposures to concentrations in the range $11 \mathrm{ppm}$ (very slight effect) to $65 \mathrm{ppm}$ (lethality: pulmonary oedema). Changes in the eye, lungs, and behaviour were noted. Eye changes were confined to erosions of the corneal epithelium and were most severe at intermediate levels of exposure. A comparison was made of the effects noted in rats with reported effects on survivors of the Bhopal disaster. Urinary thiocyanate concentrations in exposed rats were found to be reduced relative to control values.

The catastrophic consequences of the release of methyl isocyanate (MIC) from the Union Carbide plant at Bhopal in India have naturally focused attention on the toxicity of this material. It was already known to be a highly toxic and irritant material: the $\mathrm{LD}_{50}$ for four hours inhalation by rats has been reported to be $5 \mathrm{ppm}$ in one study, ${ }^{1}$ and between 30 and $60 \mathrm{ppm}$ in another. ${ }^{2}$ These numerical results by themselves, however, make only a limited contribution to the understanding of possible effects on man, ${ }^{3}$ and there is relatively little published information on the effects at sublethal concentrations, particularly as regards effects on the eye, which was found to be an important target organ in survivors of the Bhopal incident. In view of this lack of information, and in support of epidemiological studies at Bhopal, ${ }^{45}$ an investigation of these phenomena in rats after inhalation of sublethal concentrations of MIC was undertaken.

In addition to the lack of information on the dose response, time dependence, and outcome of the sublethal effects a further problem has been the uncertainty about the metabolic or chemical breakdown products of MIC. We have previously reported that the main hydrolysis product of MIC is n, $n^{\prime}$-dimethyl urea. $^{5}$ We also suggested that formation of some toxic materials by reaction of MIC with endogenous substances could occur.

On the other hand, some reports of studies on exposed survivors in India have suggested that metabolism to cyanide is important, that urinary thiocyanates are raised, and that thiosulphate is a useful treatment. ${ }^{6}$ We therefore decided to examine the urinary thiocyanate concentrations of control and exposed rats. The following report describes the initial results of this study.

\section{Methods}

Male Lister hooded rats (weight $170-200 \mathrm{~g}$ ) were exposed by inhalation to air containing various concentrations of MIC. This strain was chosen in preference to the more usual albino strains since effects on the eye and related neural pathways were of particular interest. Albino mammals are generally found to have abnormalities of those parts of the central nervous system concerned with vision and were therefore considered unsuitable subjects for these experiments. A two hour single acute exposure was chosen as the most appropriate model for the type of exposure experienced in India, and also of most direct relevance to other possible accidental exposures. No attempt was made to determine an accurate $\mathbf{L D}_{50}$ value, since this is known. Instead, for this initial study, animals were exposed in pairs to different concentrations, starting at a level expected to have minimal effects during the two hour exposure period, and stopping once the $\mathrm{LD}_{50}$ range had been reached. In this way it was hoped to obtain the maximum information with exposure of the minimum number of animals to this highly noxious material.

Exposures were performed in a glass chamber (in two cases with urine and faeces collectors, see below) through which an airflow of $101 \mathrm{~min}$ was maintained. This air was previously filtered through a charcoal 
Table 1 Effect of exposure to MIC on breathing and behaviour

\begin{tabular}{|c|c|c|c|}
\hline \multicolumn{2}{|c|}{ Dose (ppm MIC) Animal Nos } & \multirow{2}{*}{$\begin{array}{l}\text { Observations: breathing } \\
\text { Breathing normal, } \approx 2 \mathrm{~Hz} \\
\text { Slight slowing of breathing rate }\end{array}$} & \multirow{2}{*}{$\begin{array}{l}\text { Behaviour } \\
\begin{array}{l}\text { Normal } \\
\text { Sedative effect, reversed immediately at } \\
\text { end of exposure }\end{array}\end{array}$} \\
\hline $\begin{array}{l}\text { Air control } \\
11\end{array}$ & $\begin{array}{l}11,12 \\
1,2\end{array}$ & & \\
\hline 21 & 3,4 & $\begin{array}{l}\text { Sensory response: breathing slow and } \\
\text { irregular. Reversed immediately at } \\
\text { end of exposure }\end{array}$ & $\begin{array}{l}\text { Prounounced sedative effect: animals } \\
\text { asleep or unconscious (difficult to } \\
\text { arouse by tapping chamber), recovered } \\
\text { immediately at end of exposure. Animal } 3 \\
\text { suffered from diarrhoea }\end{array}$ \\
\hline 31 & 5,6 & $\begin{array}{l}\text { Breathing very slow }(0 \cdot 3-0 \cdot 5 \mathrm{~Hz}) \text { and irregular. } \\
\text { Breathing still laboured } 20 \mathrm{~h} \text { after exposure } \\
\text { but normal after } 48 \mathrm{~h}\end{array}$ & $\begin{array}{l}\text { Sedative effect, but effort in breathing leading } \\
\text { to greater arousal. Animals appeared asleep, } \\
\text { but restless. Considerably more sensitive to } \\
\text { ether anaesthesia } 20 \mathrm{~h} \text { after exposure }\end{array}$ \\
\hline 65 & 7,8 & $\begin{array}{l}\text { Breathing very slow and irregular: some } \\
\text { reversal of effect after exposure, but } \\
\text { severe respiratory distress noted } 20 \mathrm{~h} \text { later. } \\
\text { No } 8 \text { died } 45 \mathrm{~h} \text { after exposure. No } 7 \text { still } \\
\text { distressed at } 50 \mathrm{~h} \text { when killed }\end{array}$ & $\begin{array}{l}\text { Sedative effect, but also arousal due to irritation } \\
\text { during exposure. Extremely sensitive to } \\
\text { anaesthesia } 20 \mathrm{~h} \text { after exposure }\end{array}$ \\
\hline $200(10 \mathrm{~min})$ & 9,10 & $\begin{array}{l}\text { Severe irritation with coughing and slow } \\
\text { breathing rate: slightly laboured breathing } \\
\text { at } 20 \mathrm{~h} \text { after exposure, but normal at } 48 \mathrm{~h}\end{array}$ & $\begin{array}{l}\text { Severe irritation and coughing noted, but } \\
\text { sedation pronounced. More sensitive than } \\
\text { control to ether anaesthesia } 20 \mathrm{~h} \text { after exposure }\end{array}$ \\
\hline
\end{tabular}

filter to remove organic contaminants but was not dried. Airflow was maintained by a stainless steel bellows pump. MIC was introduced from a microsyringe into the airstream at a steady rate by infusion pump and the atmospheric concentration monitored at the chamber outlet by Miran infrared spectrometer. A continuous chart record of concentration was obtained. Effluent airflow from the system was directed through a scrubber system with a continuous flow of $\mathcal{G}$ water to remove MIC from the airstream before dis- 음 charge to the atmosphere. In addition to the two hour exposure series a single experiment was performed $\square$ with a ten minute exposure to a much higher concentration, which was below lethal for this duration.

The highest concentration two hour exposure and the air control exposure were performed in a glass

Table 2 Effect of exposure to MIC on the cornea and other eye structures

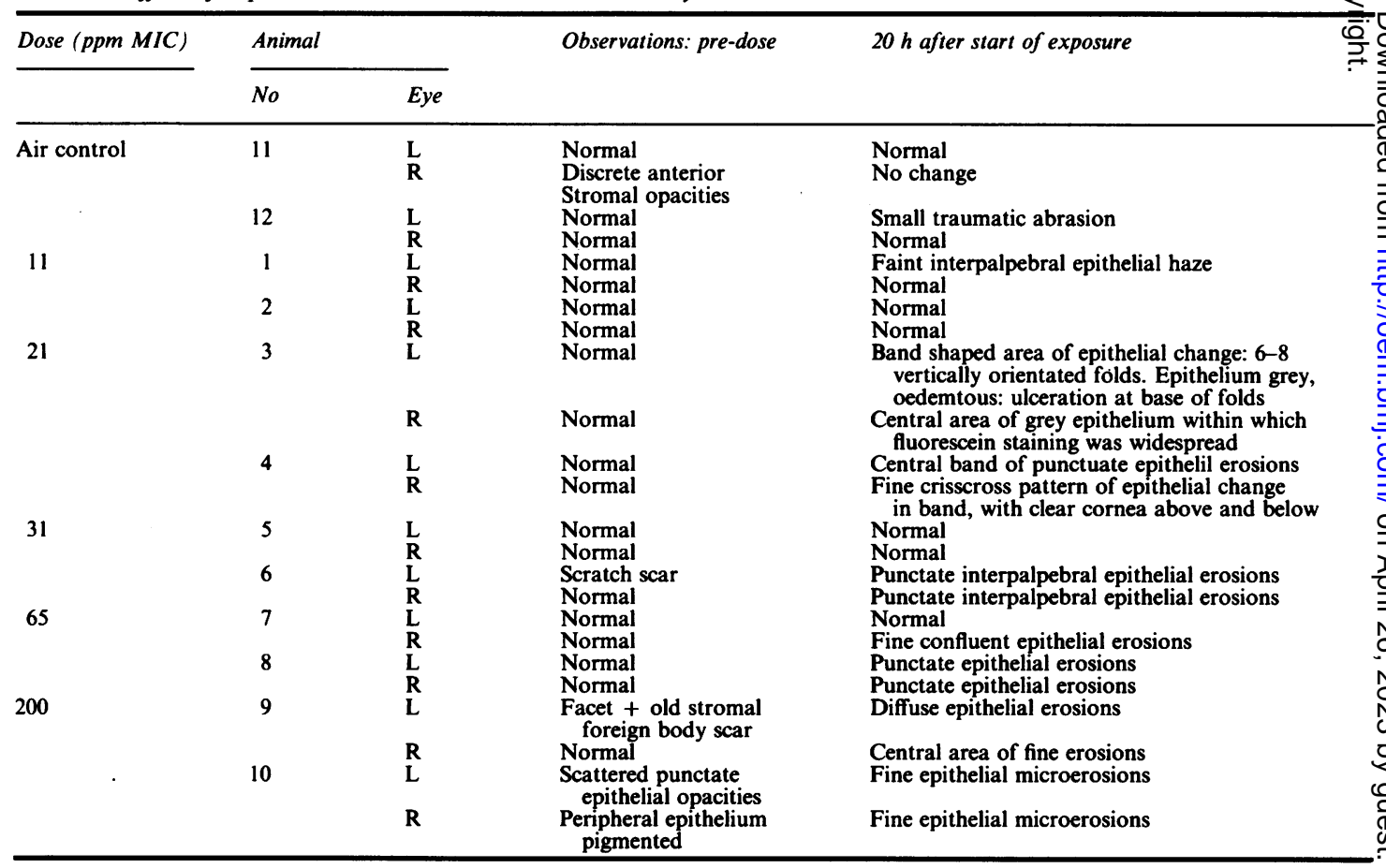


chamber with urine and faeces collectors to provide uncontaminated urine samples for thiocyanate analysis. The animals remained in the chamber with clean air at a reduced flow rate for the remainder of a 24 hour period. Measurement of urinary thiocyanate was by the method of Aubry et al. ${ }^{7}$

The eyes of the animals were examined before and 20 hours after exposure, under light anaesthesia with ether. Biomicroscopic examination was performed with a Haag-Streit slit lamp microscope, and $1 \%$ fluorescein drops were applied to stain damaged corneal epithelium. The pupils were dilated with $10 \%$ phenylephrine drops to facilitate examination of the lens.

\section{Results}

Tables 1 and 2 record the actual mean concentrations of MIC produced in the chamber during exposures, and the observations of effects on breathing, behaviour, and eyes. After exposure, abnormalities of the corneal epithelium were noted, particularly at intermediate exposure levels, but no animal showed abnormalities of the lens or other internal structures of the eye. At the highest concentration $(65 \mathrm{ppm})$ to which rats were exposed for two hours, one of the two animals died 45 hours after exposure: the other showed severe and persistent respiratory distress and was therefore killed at 50 hours. Postmortem examination of both animals showed haemorrhagic patches on the lungs, particularly the upper lobes, and the presence of fluid in the lungs and bronchi. Other organs appeared normal. The lungs of both animals were fixed for histology and examination of sections confirmed the diagnosis of pulmonary oedema and petechial haemorrhages. The remaining animals all appeared normal after 48 hours apart from eye changes, and were retained for observation of the long term outcome of these effects.

Urinary thiocyanate concentrations and 24 hour output are reported in table 3 . The urinary concentration and 24 hour output of thiocyanate in the exposed animals were substanitially lower than the control results (urines from two animals were collected over 24 hours and pooled).

\section{Discussion}

MIC at low concentrations caused severe sensory irri- tation, leading to slowing of the breathing rate from about $2 \mathrm{~Hz}$ to about $0.5 \mathrm{~Hz}$ : breathing also became irregular and laboured. This is similar to the effect of other respiratory irritants on the rat. ${ }^{8}$ Additionally, however, there appeared to be a pronounced narcotic or sedative effect that produced unconsciousness at low concentrations such as $11 \mathrm{ppm}$, which caused only minimal changes in the eye or breathing rate. This was masked at higher concentrations of MIC by the arousal resulting from respiratory distress. At these higher concentrations the sensory response of the respiratory system was accompanied by damage shown by persistent respiratory distress and pulmonary oedema, which was fatal in one case. After sublethal doses, the respiratory problems resolved spontaneously and apparently completely; the narcotic effect was reversed on cessation of exposure, but a residual neurological or pulmonary change may be indicated by the hypersensitivity to ether anaesthesia 20 hours later, which is noted in table 1 . Allowing for the interaction of these effects, there appears to be a progressive trend in the relation between dose and degree of response for the respiratory and central nervous system effects, so far as may be determined from qualitative observations. By contrast, the severity of effect on the eye was considerably greater at intermediate levels of exposure, suggesting that at high doses some protective response was evoked which, though effective in reducing damage to the corneal epithelium, was insufficiently evoked by lower levels that none the less caused superficial eye damage. In all cases the eye damage observed was confined to the epithelial layer.

When these observations are compared with those recorded in a survey of effects on the survivors of the Bhopal incident ${ }^{45}$ it is apparent that there is a clear relation between the animal and human data. In both cases the fatal effects related to damage to the lungs, and there appears to be a simple relation between the severity of this effect and the degree of exposure. ${ }^{45}$ On the other hand, the effects on the eye in the rat appeared most severe at intermediate exposure levels, again mirroring the observations in Bhopal. The damage caused to the eye in both rats and man was superficial in character, as expected from the highly reactive nature of MIC and the short lifetime therefore expected in vivo. ${ }^{5}$ Findings such as dizzyness or unconsciousness, nausea, and other central nervous

Table 3 Urinary thiocyanate after exposure to $65 \mathrm{ppm}$ methyl isocyanate for two hours

\begin{tabular}{|c|c|c|c|c|c|}
\hline \multirow[t]{2}{*}{ Sample } & \multirow[t]{2}{*}{ Creatine (nmol/l) } & \multicolumn{2}{|c|}{ Thiocyanate (ug/ml) } & \multirow{2}{*}{$\begin{array}{l}\text { Volume }(\mathrm{ml}) \\
(2 \text { rats })\end{array}$} & \multirow{2}{*}{$\begin{array}{l}24 \text { h output } \\
\text { ( } \mu \text { g per rat })\end{array}$} \\
\hline & & Measured & Corrected & & \\
\hline $\begin{array}{l}\text { Control } \\
\text { Exposed }\end{array}$ & $\begin{array}{l}6 \cdot 0 \\
2 \cdot 0\end{array}$ & $\begin{array}{l}6 \cdot 6 \\
0 \cdot 5\end{array}$ & $\begin{array}{l}1 \cdot 7 \\
0 \cdot 3\end{array}$ & $\begin{array}{l}9 \\
8\end{array}$ & $\begin{array}{l}7 \cdot 7 \\
1 \cdot 2\end{array}$ \\
\hline
\end{tabular}


system related phenomena, and diarrhoea, are seen principally among survivors at Bhopal who suffered intermediate exposures. In the rat similar responses were apparent at intermediate dose levels but were masked or reversed at the highest concentrations. From this correlation of effects and dose dependence two initial conclusions may be drawn. Firstly, the use of death rates and incidence of pulmonary damage as a crude index of exposure in the Bhopal epidemiological study (in the absence of more definite measurements) is supported. Secondly, it is apparent that the sublethal acute effects in the rat offer a useful model of the effects on man, which will be exploited in further work to clarify epidemiological findings and to investigate possible long term outcomes of exposure to MIC. In view of the evident correspondence between acute toxic effects in man and rat, it does not appear unreasonable to use the rat as a model for investigations of other aspects of MIC toxicology, including metabolism.

On the basis of the thiocyanate data presented here there are no grounds for asserting a role for conversion to cyanide, or for the usefulness of thiosulphate treatment and the measurement of urinary thiocyanate concentrations. There is an important control level of thiocyanate in the urine of both rat and man resulting from endogenous metabolism and the conversion of dietary and other sources of cyanides. The reduction of thiocyanate concentrations below normal in the exposed rats probably relates to the inhibition of general intermediary metabolism and food intake by the sedative and toxic effects of MIC or its products. This finding is consistent with the absence of a chemically plausible route for the conversion of MIC to cyanide, either in vivo or in vitro. There appear to be three possible explanations if urinary thiocyanate concentrations are indeed raised in Bhopal survivors and visitors. Firstly, there could be a "rebound" effect after inhibition of endogenous thiocyanate metabolism by exposure to MIC.
(This could explain the effect in survivors but not in subsequent visitors to the area.) Secondly, the raised thiocyanate excretion may be related to some other environmental contaminant or dietary factor affecting the population. Thirdly, some additional material which can act as a source of cyanides may have been released during the course of the accident. We are not a present able to distinguish between these possibilities, although work is in progress to evaluate the time course of the change in thiocyanate excretion after MIC exposure of rats.

We thank Dr C J Wagner, MRC Pneumoconiosis Unit, Cardiff, for examining the specimens of rat lung tissue and $\mathrm{Mr} \mathbf{C ~ J}$ Wells and Miss A Dixon, TUC Centenary Institute of Occupational Health, for help with the chemical analysis.

\section{References}

${ }^{1}$ Kimmerle R, Eben A. Zur Toxicät von Methylisocyanat und desen quantitativer Bestimmung in der Luft. Archiv für Toxicologie 1964;20:235.

${ }^{2}$ Smyth HF, Carpenter CP, Weil CS, Pozzani UC, Striegel JA, Nycum JS. Range-finding toxicity data: list VII. Am Ind Hyg Assao $J$ 1969;30:470-6.

${ }^{3}$ Salmon AG. Does acute toxicology tell us anything useful? $\mathrm{Br} J$ In Med 1985;42:577-8.

${ }^{4}$ Andersson N, Kerr Muir M, Mehra V. Bhopal eye. Lancest 1984;ii:1481.

${ }^{5}$ Andersson N, Kerr Muir M, Salmon AG, et al. Bhopal disaster: eye follow-up and analytical chemistry. Lancet 1985;i:761-2.

${ }^{6}$ For example. The Guardian 198513 May:8.

${ }^{7}$ Aubry JC, Swysen M, Bastenier H, Heuse A. Method for determining urinary thiocyanates by a modified method of Lundquist. Archives Belges de Medecine Social, Hygiene, Medecine du Travail et Medecine Legal 1982;40:321-30.

${ }^{8}$ Alarie Y. Bioassay for evaluating the potency of airborne sensory irritants and predicting acceptable levels of exposure in man. Food and Cosmetic Toxicology 1981;19:623-6. 